\title{
CpG-oligodeoxynucleotides inhibit RSV-enhanced allergic sensitisation in guinea pigs
}

\author{
F. Tayyari*, T.C. Sutton*, H.E. Manson ${ }^{\#}$ and R.G. Hegele*
}

ABSTRACT: Experimental respiratory syncytial virus (RSV) infection of guinea pigs is associated with enhanced allergic sensitisation to inhaled ovalbumin (OA) and low-level viral persistence in the lungs. Based on the T-helper (Th)1/Th2 paradigm, in which a Th2 shift is characteristic of an allergic response and less effective anti-viral immunity, the effects of immunotherapy with synthetic cytosine phosphate-guanine-oligodeoxynucleotides (CpG-ODN), which are potent Th1 stimuli, on OA sensitisation with and without RSV infection were evaluated.

Measurements included quantitative histology for airway inflammation by T-cells and eosinophils, semiquantitative RT-PCR for lung Th1/Th2 balance (interferon (IFN)- $\gamma /$ interleukin (IL)-5 mRNA ratios), and serology for circulating titres of OA-specific immunoglobulin (Ig) $G_{1}$ antibodies. RSV antigens were identified in lung tissue sections by immunohistochemistry.

CpG-ODN immunotherapy did not prevent OA sensitisation of guinea pigs; however, in RSVinfected, OA-sensitised animals, CpG-ODN administration was associated with significant reductions of airway T-cells and eosinophils, increased lung IFN- $\gamma /$ IL-5 ratios, and decreased OA-specific $\operatorname{lgG}_{1}$ antibody titres to levels observed in uninfected, OA-sensitised animals. Viral antigens were identified in a similar proportion of the lungs of RSV-infected animals, irrespective of CpG-ODN immunisation status.

In conclusion, cytosine phosphate-guanine-oligodeoxynucleotides immunotherapy protects guinea pigs against respiratory syncytial virus-enhanced ovalbumin sensitisation and might be a relevant intervention in the context of post-bronchiolitis allergic sensitisation in children.

KEYWORDS: Acute bronchiolitis, allergy, cytosine phosphate-guanine-oligodeoxynucleotides, respiratory syncytial virus

$\mathbf{R}$ espiratory syncytial virus (RSV) is the most common cause of acute bronchiolitis, a serious lung infection that affects mainly infants and young children [1]. Children who are hospitalised for acute bronchiolitis often develop sequelae of recurrent wheezing and symptoms of asthma, but the mechanisms responsible are poorly understood [1]. Prospective studies in children have implicated RSV infection in the development of allergic sensitisation [2, 3], and experiments in RSVinfected mice have also reported virus-enhanced airway responsiveness and allergic airway inflammation related to ovalbumin (OA) sensitisation [4].

The current authors have used guinea pigs as an animal model of experimental RSV bronchiolitis [5] and OA sensitisation [6], and have observed significantly higher titres of circulating OAspecific immunoglobulin $(\mathrm{Ig}) \mathrm{G}_{1}$ antibodies (the major class of Ig that mediates allergic responses in these guinea pigs [7]) in animals that had the combination of RSV infection and OA exposures, in comparison with OA exposures alone [8]. Airway inflammation by T-cells and eosinophils is a feature of acute RSV infection in guinea pigs [9] and of human asthma [10]. OA-sensitised guinea pigs have increased airway eosinophils [6, 8], but, to date, the current authors have not studied whether OA sensitisation of guinea pigs is associated with changes in airway T-cells. The combination of RSV infection and OA exposures is associated with the persistence of low levels of virus in the guinea pig lung [8], and, although RSV persistence is emerging as an area of considerable interest [11], it is unclear whether viral persistence contributes to the pathogenesis of RSV-enhanced allergic sensitisation.

Under the T-helper (Th)1/Th2 paradigm, allergic responses are characterised by a shift in Th1/Th2

\section{AFFILIATIONS}

*James Hogg iCAPTURE Centre for Cardiovascular and Pulmonary Research, and

\#Dept of Health Care and

Epidemiology, University of British Columbia, Vancouver,

$\mathrm{BC}$, Canada

CORRESPONDENCE

R.G. Hegele

James Hogg iCAPTURE Centre for

Cardiovascular and Pulmonary

Research

St. Paul's Hospital

1081 Burrard Street

Vancouver

BC

Canada V6Z 1 Y6

Fax: 16048069274

E-mail: rhegele@mrl.ubc.ca

Received

February 092004

Accepted after revision:

October 112004

\section{SUPPORT STATEMENT}

This work was supported by the Canadian Institutes of Health Research (Ottawa, ON, Canada) and the British Columbia Lung Association (Vancouver, BC, Canada). 
balance towards a Th2 response [12]. Given that experimentally infected guinea pigs [9] and a proportion of children with acute bronchiolitis [13-15] show evidence of a Th2 shift in Th1/Th2 balance during RSV bronchiolitis, it was hypothesised that RSV-associated enhancement of allergic sensitisation might be ameliorated by interventions designed to prevent a Th2 shift in lung cytokine balance. In addition, since Th1 responses are considered essential for effective anti-viral immunity [16], interventions that stimulate a Th1 response, in the context of preventing OA sensitisation, might also result in more effective RSV clearance from the lungs.

Cytosine phosphate-guanine-oligodeoxynucleotides (CpGODN) are synthetic and rich in unmethylated cytosine phosphate-guanine motifs that were originally isolated from components of bacterial DNA [17]. CpG-ODN are potent stimuli for Th1 responses in many veterinary species [18], and CpG-ODN immunotherapy has been studied as a strategy for primary prevention and the treatment of allergic disorders [19]. Therefore, the effects of administering CpG-ODN immunotherapy to guinea pigs, with and without RSV infection, at the time of OA sensitisation, were investigated.

The objectives of the current study were to examine the effects of pre-treatment of guinea pigs with CpG-ODN immunotherapy on the following: 1) subsequent RSV-enhanced allergic sensitisation to OA; 2) RSV persistence that is associated with virus-enhanced allergic sensitisation; and 3) sensitisation of animals to OA in the absence of RSV infection. These objectives were assessed by measuring: 1) airway inflammation by T-cells and eosinophils [10]; 2) ratios of interferon (IFN)- $\gamma$ (a Th1 cytokine) to interleukin (IL)-5 (a Th2 cytokine) mRNA as an index of lung Th1/Th2 balance [9]; 3) circulating titres of OA-specific $\mathrm{IgG}_{1}$ antibodies [8]; and 4) proportions of virus-inoculated animals that showed positive immunohistochemical staining for RSV antigens within lung tissue sections.

\section{MATERIALS AND METHODS \\ Animals}

Juvenile 1-month-old, female Cam Hartley guinea pigs (body weight: 250-300 g) were purchased from Charles River Laboratories (Montreal, QC, Canada), and housed under conditions of alternating 12-h light-dark cycles, in plastic cages with hypoallergenic bedding, and with free access to food and water, in accordance with standards of the Canadian Council on Animal Care (Ottawa, ON, Canada) [20]. Animals were acclimatised for 5 days before experimentation. Two experiments were designed as follows.

\section{Experiment 1: Effects of CpG-ODN immunotherapy on ovalbumin sensitisation with respiratory syncytial virus infection}

Three groups (12 animals $\cdot$ group $\left.^{-1}\right)$ of guinea pigs were studied, as follows: 1) negative controls (group 1), which are uninfected, unsensitised guinea pigs; 2) RSV + OA-positive controls, i.e. RSV infection and exposure to OA-containing aerosols; and 3) CpG-ODN + RSV + OA group, i.e. CpG-ODN immunotherapy, followed by RSV infection and exposure to OA-containing aerosols.

\section{Experiment 2: Effects of CpG-ODN immunotherapy on ovalbumin sensitisation without respiratory syncytial virus infection}

Four groups (4 animals.group ${ }^{-1}$ ) of guinea pigs were studied, as follows: 1) negative controls (group 2), which are unsensitised guinea pigs; 2) CpG-ODN group, i.e. CpG-ODN immunotherapy of naïve guinea pigs; 3) OA-positive controls, i.e. exposure to OA-containing aerosols; and 4) CpG-ODN + OA group, i.e. CpG-ODN immunotherapy, followed by exposure to OA-containing aerosols.

In experiment 2, the inclusion of a group of CpG-ODN-treated controls allowed for assessment of the effects of CpG-ODN immunotherapy in naïve animals, and the negative control group 2 allowed for comparisons of the similarity of baseline indices in groups of unsensitised, uninfected animals between the two experiments.

\section{Virus inoculation}

Virus stocks were prepared by propagation of the Long strain of subgroup A human RSV (American Type Culture Collection, Manassas, VA, USA) on human epithelial-2 cell monolayers at $37^{\circ} \mathrm{C}$ in a humidified incubator containing $5 \%$ $\mathrm{CO}_{2}$, according to methods described elsewhere [21]. The cell culture medium consisted of RPMI 1640 (Gibco, Grand Island, NY, USA), supplemented with $5 \%$ foetal bovine serum (Gibco), 1\% L-glutamine (Gibco) and 1\% Antibiotic-Antimyotic (Gibco). Virus-infected animals were inoculated with $3 \times 10^{4}$ plaque forming units of RSV in $300 \mu \mathrm{L}$ of cell culture medium, administered by intranasal instillation, while under light anaesthesia induced by $3-5 \%$ halothane inhalation [5]. Uninfected animals were similarly anaesthetised and received $300 \mu \mathrm{L}$ of cell culture medium intranasally.

\section{CpG-ODN immunotherapy}

The dose and route of CpG-ODN (CpG-ODN type B [22] number 2007, 22-mer sequence 5' TCGTCGTTGTCGTTTTGTCGTT 3'; Coley Pharmaceutical Group, Wellesley, MA, USA) administration were based on the results of a preliminary study [23], which showed maximal increases in pulmonary IFN- $\gamma /$ IL-5 mRNA ratios when guinea pigs received $100 \mu \mathrm{g}$ of CpG-ODN (in $300 \mu \mathrm{L}$ sterile normal saline, inoculated intranasally under $3-5 \%$ halothane anaesthesia), repeated twice weekly over 4 weeks, for a total of three doses. Control animals that did not receive CpG-ODN immunotherapy were given a similar regimen of sterile normal saline.

\section{Ovalbumin sensitisation and challenges}

The guinea pigs underwent OA sensitisation 7 days after administration of the final CpG-ODN dose, according to methods described elsewhere [8]. In experiment 1, the first OA exposure occurred $2 \mathrm{~h}$ after RSV or sham inoculation. Animals were placed in polycarbonate chambers for $9 \mathrm{~min}$ and exposed to an aerosol of $1 \% \mathrm{OA}$ in saline, delivered by an ultrasonic nebuliser (DeVilbiss, Somerset, PA, USA). Subsequently, 1 week after the first exposure, animals were exposed to an aerosol of $0.5 \% \mathrm{OA}$ in saline, which was repeated three times per week for 2 weeks. Negative control animals received similar exposures to saline-containing aerosols. Animals received $40 \mathrm{mg} \cdot \mathrm{kg}^{-1}$ of body weight of 
diphenhydramine hydrochloride i.p. (Sigma, St. Louis, MO, USA) 20-30 $\mathrm{min}$ before each OA challenge to prevent anaphylactic shock $[6,8]$. Then, 3 days after the last aerosol exposure, animals underwent euthanasia with an i.p. injection of $150 \mathrm{mg} \cdot \mathrm{kg}^{-1}$ sodium pentobarbital (MTC Pharmaceuticals, Cambridge, ON, Canada).

\section{Serum collection}

After euthanasia, cardiac puncture was performed to obtain heart blood. Blood was placed in serum separation tubes (Becton Dickinson, Franklin Lakes, NJ, USA) for 30-60 min at room temperature. After undergoing centrifugation at $1,000 \times g$ for $15 \mathrm{~min}$, the serum was divided into aliquots and stored at $-70^{\circ} \mathrm{C}$.

\section{Lung-tissue processing}

Lungs were removed after blood sampling. One lobe was cut into small pieces and stored in RNAlater (Qiagen $\mathrm{GmbH}$, Hilden, Germany) for cytokine RT-PCR experiments. Another lobe was inflated with a 1:1 solution of optimum cuttingtemperature compound (Miles Diagnostics Division, Elkhart, IL, USA) [24], sliced in the sagittal plane, fixed in 10\% neutralbuffered formalin and embedded in paraffin.

\section{Lung histology for airway inflammation}

Airway inflammation was evaluated by comparing the percentage of the airway wall occupied by T-lymphocytes and eosinophils $[9,10]$ between the groups of experimental animals. T-cells and eosinophils were identified on $4-\mu \mathrm{m}$-thick, formalin-fixed, paraffin-embedded lung sections, by immunostaining with polyclonal anti-CD3+ ("pan-T"-cell) antibody (Dako 0452; Dako, Glastrop, Denmark) and Hansel's method, which stains basic arginine residues of eosinophil granules [25], respectively, as per a published protocol [9]. Slides were coded such that the microscopist did not know which study group a given slide was obtained from. Images from 5-10 membranous bronchioles per animal were photographed using a digital camera (Nikon Corporation, Kanagawa, Japan) and stored as uncompressed TIFF files. The Image Pro PLUS image analysis system (Media Cybernetic Inc., Silver Spring, MD, USA) was used to place a grid over the microscopic field and count the positively stained points in all compartments of the airway wall. The ratio of positively stained points to total points in the airway wall was reported as a percentage.

\section{Respiratory syncytial virus immunohistochemistry}

Sections (4- $\mu \mathrm{m}$ thick) of formalin-fixed, paraffin-embedded lung tissues were cut onto glass slides and baked at $60^{\circ} \mathrm{C}$ for $40 \mathrm{~min}$. This was followed by antigen retrieval in Citra Buffer (Dako) and autoclaving at $121^{\circ} \mathrm{C}$ for $22 \mathrm{~min}$. Slides were placed in an Autostainer (Dako) at room temperature and incubated with normal rabbit serum for $20 \mathrm{~min}$. Slides were subsequently incubated with NCL-RSV3 mouse monoclonal RSV antibody (Novacastra Laboratories Ltd, Newcastle-upon-Tyne, UK; 1:50 dilution for $2 \mathrm{~h}$ ), followed by: two 5 -min washes in Trisbuffered saline plus $0.1 \%$ Tween 20 (TBS/Tween); incubation with secondary rabbit anti-mouse Ig for $30 \mathrm{~min}$; two 5-min washes in TBS/Tween; exposure to alkaline-phosphatase-antialkaline phosphatase reagent (Dako) for $40 \mathrm{~min}$; three 5-min washes in TBS/Tween; reaction with new fuchsin for $20 \mathrm{~min}$; a 5-min TBS/Tween wash; counterstaining with haematoxylin for $2 \mathrm{~min}$; and mounting with a coverslip. Positive controls consisted of archival lung tissue sections from a guinea pig that was euthanised 7 days post-RSV inoculation. Negative controls consisted of the same tissues incubated with rabbit Ig fraction (normal) negative control preparation (Dako; 1:50 dilution), which was substituted for the anti-RSV primary antibody. For each animal, results were reported as "positive" (i.e. RSV-specific immunostaining observed) or "negative" (i.e. no specific immunostaining observed).

\section{Semiquantitative RT-PCR}

Total RNA was extracted from $150 \mathrm{mg}$ of lung tissue kept in RNAlater (Qiagen), using the RNeasy Midi Kit (Qiagen), according to the manufacturer's instructions. Equal amounts of RNA $(0.5 \mu \mathrm{g})$ underwent reverse transcription (RT) using random hexamers (Invitrogen, Rockville, MD, USA) as primers and Moloney Murine Leukemia Virus Reverse Transcriptase (Invitrogen), according to the manufacturer's instructions. A total of $2 \mu \mathrm{L}$ of complementary DNA (nondiluted for IFN- $\gamma$ or IL-5, or 1:10 diluted in sterile distilled $\mathrm{H}_{2} \mathrm{O}$ for a constitutively expressed "housekeeping" gene, $\beta$-actin) obtained from RT was used in a $25-\mu \mathrm{L}$ PCR reaction mixture that consisted of $1 \times$ concentration PCR buffer (Qiagen), $2.5 \mathrm{mM} \mathrm{MgCl} 2$ (Qiagen), $200 \mu \mathrm{M}$ of each deoxynucleotide triphosphate (Invitrogen), $0.5 \mu \mathrm{M}$ of each flanking primer (Sigma), and 2.5 units per reaction of HotStar Taq DNA Polymerase (Qiagen). Table 1 shows primer sequences designed for PCR using Primer 3 software (Whitehead Institute for Biomedical Research, Cambridge, MA, USA) [26]. A Genbank (National Institutes of Health, Bethesda, MD, USA) search revealed a lack of significant homology between these sequences and other catalogued genes in guinea pigs and other mammals. Results of preliminary experiments (data not shown) confirmed that the complete nucleic acid sequences of PCR amplicons matched the cDNA sequences published in Genbank. Using a Robocycler 96 (Stratagene, La Jolla, CA, USA), PCR mixtures underwent denaturation for $1 \mathrm{~min}$ at $94^{\circ} \mathrm{C}(15 \mathrm{~min}$ for the first cycle), followed by annealing $\left(1 \mathrm{~min}\right.$ at $59^{\circ} \mathrm{C}, 58^{\circ} \mathrm{C}$ and $60^{\circ} \mathrm{C}$ for $\beta$-actin, IFN- $\gamma$ and IL-5, respectively) and extension ( $1 \mathrm{~min}$ at $72{ }^{\circ} \mathrm{C}, 10 \mathrm{~min}$ during the final cycle). Denaturation, annealing and extension were repeated for 30 ( $\beta$-actin) or 40 cycles (IFN- $\gamma$ and IL-5). Blank negative controls, containing distilled $\mathrm{H}_{2} \mathrm{O}$ instead of a nucleic acid template, were prepared and analysed

\begin{tabular}{|c|c|c|}
\hline TABLE 1 & $\begin{array}{l}\text { Oligonucleotide primer sequences } \\
\text { RT-PCR }\end{array}$ & or cytokine \\
\hline Target gene & Primer sequences & $\begin{array}{c}\text { Product size } \\
\text { base pairs }\end{array}$ \\
\hline IFN- $\gamma$ & $\begin{array}{c}\text { Antisense 5' AGGAGACGATTTGGCTCTGA 3' } \\
\text { Sense 5' GAAGTTCTTTGGACCTGATCG 3' }\end{array}$ & 298 \\
\hline IL-5 & $\begin{array}{c}\text { Antisense 5' CCAGAGCTTCCCCTTGTGTA 3' } \\
\text { Sense 5' TGTCTGTGTCTGTGCCATCC 3' }\end{array}$ & 215 \\
\hline$\beta$-actin & $\begin{array}{c}\text { Antisense 5' GGGGTGTTGAAAGTCTCGAA 3' } \\
\text { Sense 5' ACTGGGACGACATGGAGAAG 3' }\end{array}$ & 157 \\
\hline
\end{tabular}

IFN: interferon; IL: interleukin 
at the same time. PCR products underwent electrophoresis on ethidium bromide-stained $2 \%$ agarose gels and were visualised under ultraviolet light. The optical density (OD) of bands was measured using an Eagle Eye digital image capture and analysis system (Stratagene) and values for cytokines were normalised to the corresponding OD for $\beta$-actin.

\section{Measurement of ovalbumin-specific immunoglobulin $G_{1}$ antibodies}

OA-specific $\operatorname{IgG}_{1}$ was measured using an ELISA method, as previously described [8], in which antibody titres were determined at $450 \mathrm{~nm}$ in a Titertek Multiskan Plus MK2 ELISA microtitre plate reader (Titertek, Huntsville, AL, USA). Titres were determined as the greatest dilution of serum to produce an OD of $\geqslant 0.1$ units above control values, in which controls consisted of sera obtained from unexposed, naïve animals. This endpoint of $0.1 \mathrm{OD}$ units above control values was predetermined from a point titration of the least amount of guinea pig IgG that can be detected by the method using the same dilution of horseradish peroxidaseconjugated, anti-guinea pig $\operatorname{IgG}_{1}$ (heavy-chain specific; Bethyl Laboratories, Montgomery, TX, USA). At this cut-off level, the lower limit of detection was 1.5-2-times higher than background values [8].
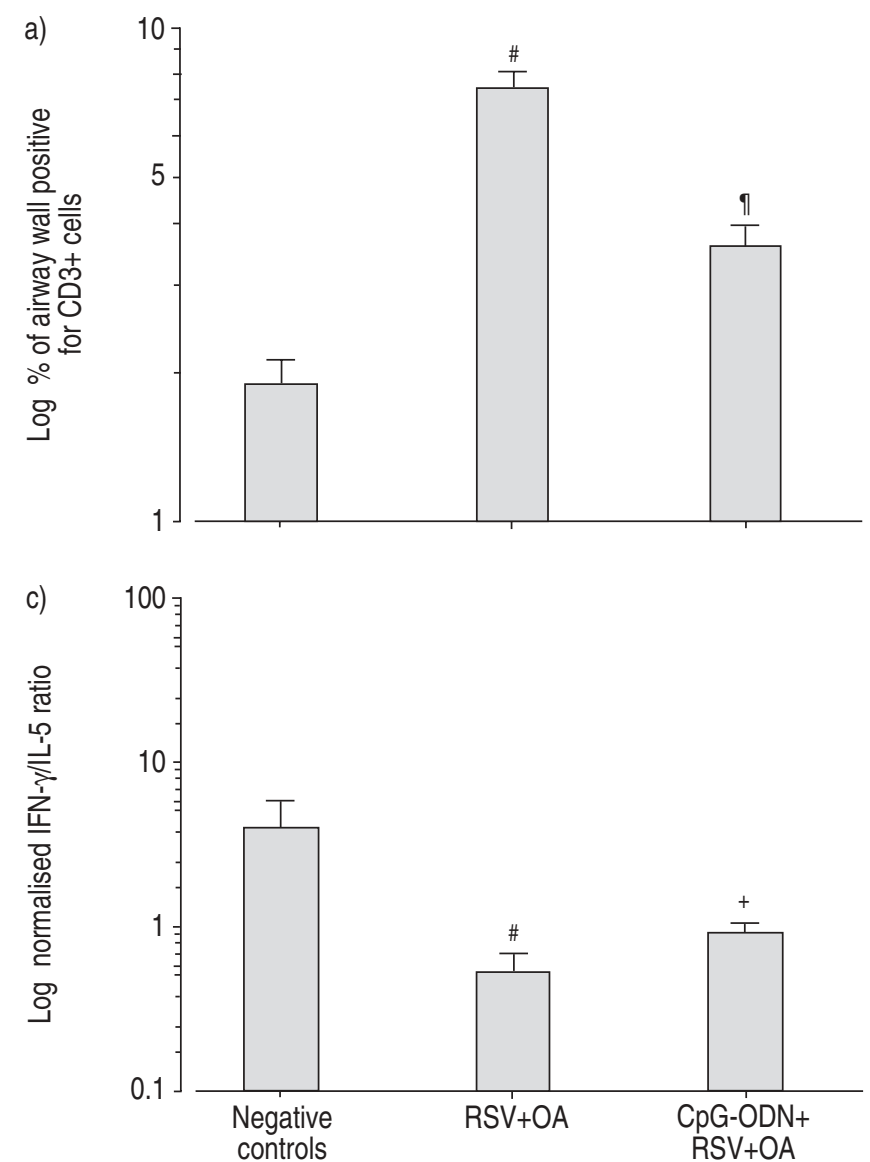

\section{Data analysis}

Data for percentages of airway wall occupied by T-cells and eosinophils, cytokine ratios and reciprocal titres of OA-specific $\mathrm{IgG}_{1}$ antibodies underwent logarithmic transformation to obtain an improved approximation of normal distribution [9]. For groups of animals studied within a given experiment and between the two experiments, one-way ANOVA was used to compare the mean percentages of the airway wall occupied by T-cells and eosinophils, normalised lung cytokine ratios and mean reciprocal OA-specific $\mathrm{IgG}_{1}$ antibody titres between groups, with a p-value of $<0.05$ considered statistically significant. If statistically significant by ANOVA, inter-group comparisons were further characterised by paired t-tests, with a level of significance set at a p-value of $<0.05$ (two-tailed), after correction for multiple comparisons by a Bonferroni method [27]. In experiment 1, the proportion of virusinoculated animals within experimental groups that showed positive immunostaining for RSV antigens were compared by use of the Fisher's exact test [28]. A two-tailed p-value of $<0.05$ was considered to be statistically significant.

\section{RESULTS}

One guinea pig from the RSV + OA-positive control group of experiment 1 underwent euthanasia 2 days after the second
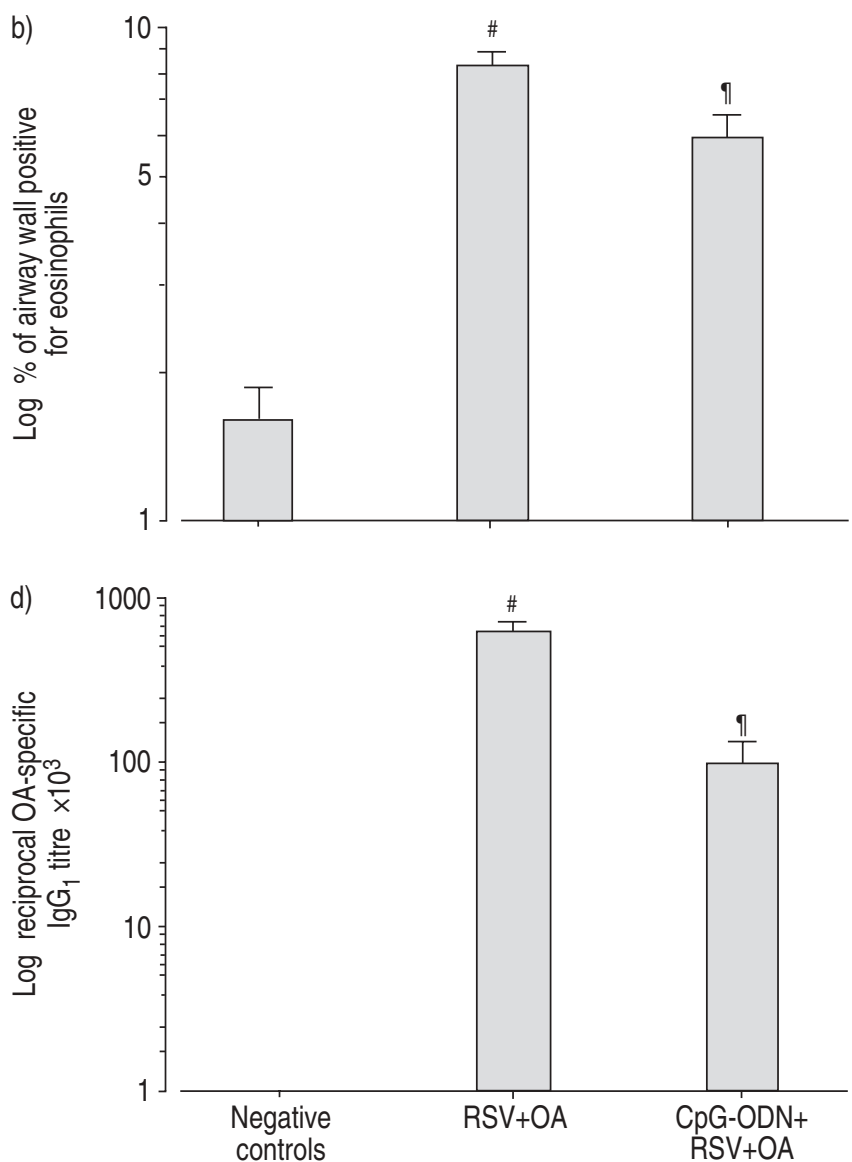

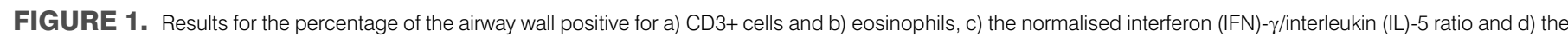

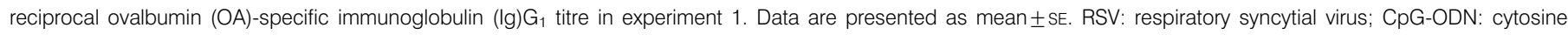

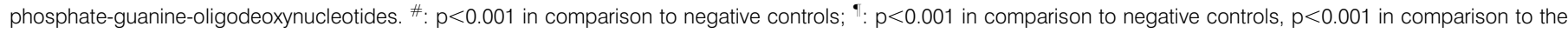
$\mathrm{RSV}+\mathrm{OA}$ group; ${ }^{+}: \mathrm{p}<0.001$ in comparison to negative controls, $\mathrm{p}<0.02$ in comparison to the RSV + OA group 
OA exposure because of decreased activity and poor feeding. Otherwise, procedures were well tolerated by all other animals studied.

\section{Experiment 1: Effects of CpG-ODN immunotherapy on ovalbumin sensitisation with respiratory syncytial virus infection}

Figure 1 summarises the results of the histological assessment of airway inflammation by a quantitative point-counting method, RT-PCR for IFN- $\gamma /$ IL-5 mRNA ratios and serology for OA-specific $\operatorname{IgG}_{1}$ antibodies for experiment 1 . Both the RSV + OA-positive control group and the CpG-ODN + RSV + OA intervention group had significant increases in the percentage of the airway wall occupied by T-cells and eosinophils, in comparison with the group of uninfected, unsensitised animals in negative control group $1(p<0.001)$. However, the mean percentages of airway T-cells and eosinophils in the CpG-ODN $+\mathrm{RSV}+\mathrm{OA}$ group were significantly lower than for the RSV + OA-positive controls $(\mathrm{p}<0.001)$.

Concerning the IFN- $\gamma / \mathrm{IL}-5$ mRNA ratios, the RSV + OApositive controls had a Th2 shift in lung Th1/Th2 balance in comparison with the negative control group $1(\mathrm{p}<0.001)$. The CpG-ODN + RSV + OA group showed "intermediate" IFN- $\gamma$ / IL-5 ratios that were significantly higher than the RSV + OApositive control group $(\mathrm{p}<0.02)$ and lower than the negative control group $1(\mathrm{p}<0.001)$.

OA-specific $\mathrm{IgG}_{1}$ antibodies were detected in the sera of all RSV-inoculated animals. Mean reciprocal titres of OA-specific $\mathrm{IgG}_{1}$ were significantly lower in the $\mathrm{CpG}-\mathrm{ODN}+\mathrm{RSV}+\mathrm{OA}$ group in comparison with RSV + OA-positive controls $(\mathrm{p}<0.001)$. No OA-specific $\mathrm{IgG}_{1}$ antibodies were detected in the sera obtained from unsensitised animals in the negative control group $1(\mathrm{p}<0.001)$.

RSV antigens were detected by immunohistochemistry in nine out of 11 animals in the RSV + OA-positive control group and eight out of 12 animals in the CpG-ODN + RSV + OA intervention group $(p=0.64)$. As shown in figure 2, positive RSV immunostaining was observed in several types of lung cells, which included cells within the airway wall, bronchusassociated lymphoid tissue and cells that had the appearance of alveolar macrophages. There were no apparent differences in the types of cells showing positive RSV immunostaining between the RSV + OA-positive control group and the CpGODN + RSV + OA group; however, quantification was not undertaken owing to the low numbers of positively stained cells within the lung sections examined. No false-positive RSV immunostaining was observed in any negative control sections examined.

\section{Experiment 2: Effects of CpG-ODN immunotherapy on ovalbumin sensitisation without respiratory syncytial virus infection}

Figure 3 summarises the results of the histological assessment for airway inflammation by point counting, RT-PCR for lung IFN- $\gamma /$ IL-5 mRNA ratios and serology for OA-specific $\operatorname{IgG}_{1}$ antibodies in experiment 2. Groups of animals that were exposed to OA, irrespective of CpG-ODN immunisation status, had significant increases in the percentage of airway wall occupied by T-cells and eosinophils, in comparison with animals in negative control group $2(\mathrm{p}<0.05$ and $\mathrm{p}<0.002$, respectively) and animals given $\mathrm{CpG-ODN}$ only $(\mathrm{p}<0.001$ and $\mathrm{p}<0.03$, respectively). The mean percentages of the airway occupied by T-cells and eosinophils in the CpG-ODN + OA group were similar to those of OA-exposed positive controls $(p=0.71$ and $p=0.81$, respectively). The group of animals given CpG-ODN only had a significantly lower percentage of the airway occupied by T-cells in comparison with negative control group $2(\mathrm{p}<0.05)$, and these two groups showed similar percentages of airway eosinophils $(p=0.75)$.

Both the OA-sensitised positive control group and the CpGODN + OA group had significantly lower lung IFN- $\gamma /$ IL-5 mRNA ratios in comparison with negative control group 2, which is indicative of a Th2 shift $(\mathrm{p}<0.001)$. IFN- $\gamma /$ IL-5 mRNA ratios were similar between the $\mathrm{CpG}-\mathrm{ODN}+\mathrm{OA}$ group and the OA-exposed positive controls $(p=0.67)$. Animals receiving CpG-ODN only had a significantly higher lung IFN- $\gamma /$ IL-5 mRNA ratio than negative control group $2(p<0.05)$, which is
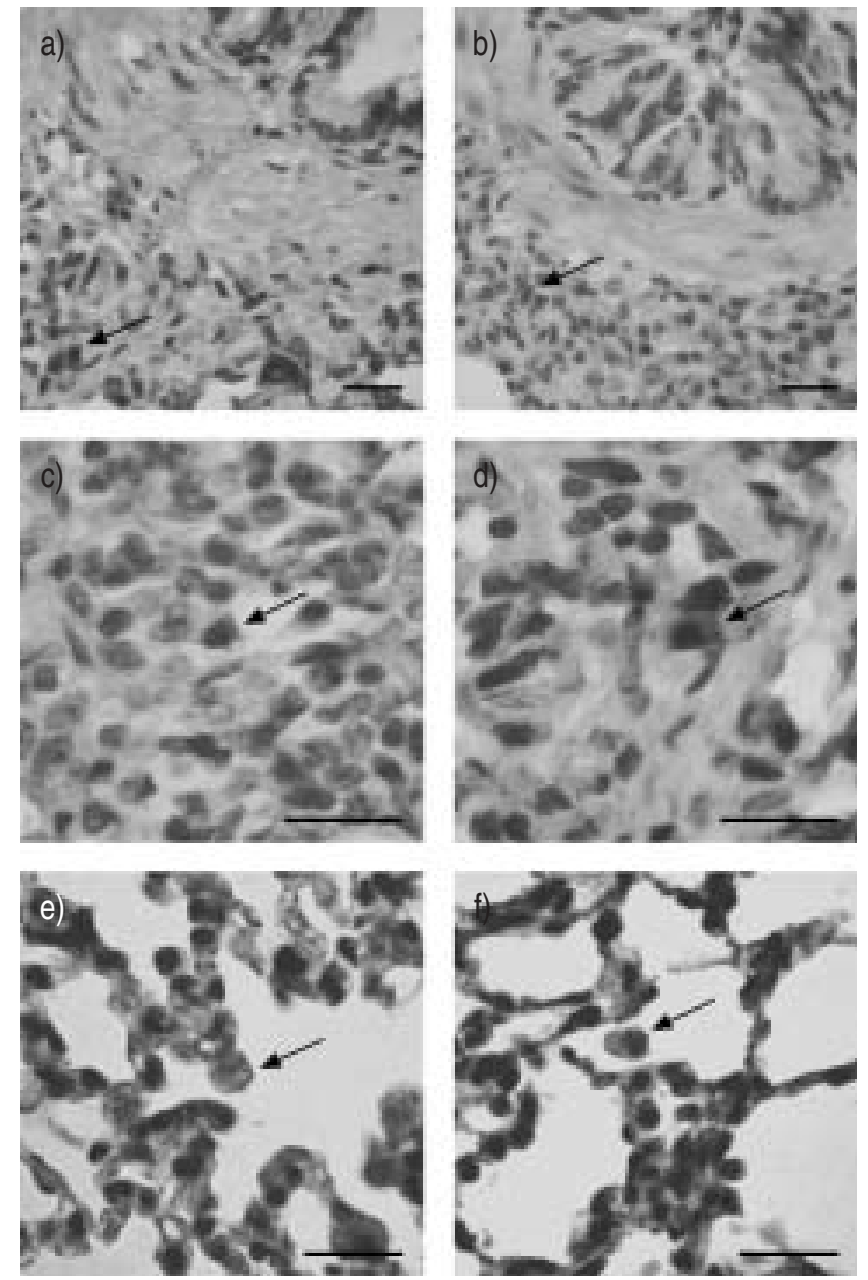

FIGURE 2. Photomicrographs of guinea pig lung sections from the respiratory syncytial virus + ovalbumin control group (a, c, e) and cytosine phosphate-guanineoligodeoxynucleotides group ( $b, d, f)$ from experiment 1 . There is positive immunostaining (arrows) in cells within the airway adventitia (a, b), bronchusassociated lymphoid tissue (c, d), and alveolar macrophage-like cells (e, f), which are indicative of intracellular viral antigens. Scale bars $=50 \mu \mathrm{m}$. 



FIGURE 3. Results for the percentage of the airway wall positive for a) CD3+ cells and b) eosinophils, c) the normalised interferon (IFN)- $\gamma /$ interleukin (IL)- 5 ratio and d) the reciprocal ovalbumin (OA)-specific immunoglobulin $(\mathrm{Ig}) \mathrm{G}_{1}$ titre in experiment 2. Data are presented as mean \pm SE. CpG-ODN: cytosine phosphate-guanineoligodeoxynucleotides. ${ }^{\#}$ : $p<0.05$ in comparison to negative controls; ${ }^{\circ}$ : $p<0.05$ in comparison to negative controls, $p<0.001$ in comparison to CpG-ODN-only group; ${ }^{+}$: $p<0.002$ in comparison to negative controls, $p<0.03$ in comparison to $\mathrm{CpG}-\mathrm{ODN}$-only group; ${ }^{\S}$ : $p<0.001$ in comparison to negative controls, $p<0.003$ in comparison to CpG-ODN-only group; ${ }^{f}: \mathrm{p}<0.001$ in comparison to negative controls, $p<0.001$ in comparison to CpG-ODN-only group.

indicative of a Th1 shift in association with the CpG-ODN immunotherapy of naïve animals.

Circulating OA-specific antibodies were detected only in OAsensitised animals $(p<0.001$ in comparison with the two groups of animals not exposed to OA). Mean reciprocal titres of OA-specific $\mathrm{IgG}_{1}$ antibodies were similar between the CpGODN + OA group and the OA-sensitised positive controls $(\mathrm{p}=0.98)$.

\section{Inter-group comparisons for CpG-ODN immunotherapy and} respiratory syncytial virus-enhanced allergic sensitisation

Table 2 shows the associated p-values from comparisons of the groups of animals studied in experiments 1 and 2. Importantly, the negative control groups of guinea pigs in experiments 1 and 2 were comparable, in that there were no statistically significant differences in any of the outcome variables examined. The combination of RSV infection and OA sensitisation was associated with significantly higher mean percentages of the airway wall occupied by T-cells and eosinophils, lower lung IFN- $\gamma / \mathrm{IL}-5$ mRNA ratios and increased circulating titres of OA-specific $\operatorname{IgG}_{1}$ antibodies than that observed in uninfected, OA-sensitised guinea pigs.
Animals that received CpG-ODN immunotherapy prior to the combination of RSV infection and OA sensitisation had similar levels of airway inflammatory cells, cytokine ratios and antibody titres to those observed in uninfected, OA-sensitised guinea pigs.

\section{DISCUSSION}

To the current authors' knowledge, this is the first study to examine the effects of CpG-ODN immunotherapy on allergic sensitisation in guinea pigs, with or without associated RSV infection. The results show that the pre-treatment of juvenile guinea pigs with $\mathrm{CpG}-\mathrm{ODN}$ immunotherapy protected animals against the enhanced effects on airway inflammation by T-cells and eosinophils, Th2 shift in ratios of lung IFN- $\gamma /$ IL-5 mRNA, and increased circulating titres of OA-specific $\operatorname{IgG}_{1}$ antibodies associated with the combination of RSV infection and OA exposure, in comparison to those observed with OA exposure in the absence of viral infection. The level of protection conferred by CpG-ODN immunotherapy is consistent with inhibition of the viral contribution to the overall extent of OA sensitisation. The results also show that CpG-ODN immunotherapy did not protect guinea pigs against the effects of OA exposure alone, despite the intervention producing a 
TABLE 2 Inter-group comparisons between experiments 1 and $2^{\#}$

\begin{tabular}{lcccc} 
Groups compared & $\begin{array}{c}\text { Airway wall } \\
\text { CD3+ cells } \%\end{array}$ & $\begin{array}{c}\text { Airway wall } \\
\text { eosinophils } \%\end{array}$ & $\begin{array}{c}\text { Normalised } \\
\text { IFN- } \gamma / \text { IL-5 ratios }\end{array}$ & $\begin{array}{c}\text { OA-specific IgG } \\
\text { antibody titres }\end{array}$ \\
\hline Negative control group 1 versus negative control group 2 & 0.96 & 0.75 & 0.80 & 1.0 \\
RSV+OA versus OA & $<0.001$ & 0.018 & 0.01 & 0.025 \\
RSV+OA versus CpG-ODN+OA & 0.03 & 0.048 & 0.011 & 0.006 \\
CpG-ODN+RSV+OA versus OA & 0.87 & 0.59 & 0.84 & 0.51 \\
CpG-ODN+RSV+OA versus CpG-ODN+OA & 0.63 & 0.50 & 0.62 & 0.39 \\
\hline
\end{tabular}

IFN: interferon; IL: interleukin; OA: ovalbumin; Ig: immunoglobulin; RSV: respiratory syncytial virus; CpG-ODN: cytosine phosphate-guanine-oligodeoxynucleotides. \# expressed as p-values.

Th1 shift in the lungs of naïve animals. These findings in guinea pigs may be relevant to developing innovative strategies for protecting the subgroup of children who develop RSV-enhanced allergic sensitisation [2, 3].

The current results confirm previous observations of increased airway eosinophils and circulating titres of OA-specific $\operatorname{IgG}_{1}$ antibodies in guinea pigs exposed to aerosolised OA [8], and extend the previous findings that $\mathrm{OA}$ sensitisation of guinea pigs was associated with increases in airway T-cells, with the Th2 shift in lung Th1/Th2 balance consistent with the development of an allergic response [12]. Importantly, the current results show that the protection conferred by CpGODN immunotherapy was not related to enhanced clearance of RSV from the guinea pig lung. However, a limitation of the immunohistochemical staining method is the inability to distinguish between viral antigens associated with infectious, replicating RSV or with an inactivated virus, thereby precluding comparisons of viral load between groups. In addition, a limitation of the guinea pig model is the relative paucity of species-specific reagents available to further characterise the types of cells that contained viral antigens. Despite these limitations, the confirmation of the persistence of viral protein in the guinea pig lung is consistent with the current authors' previous observations in this animal model [8].

Possible mechanisms for the protective effects of CpG-ODN immunotherapy on RSV-enhanced OA sensitisation include CpG-ODN acting as a "danger signal" to activate innate immune defences [19] and/or inhibiting the Th2 shift attributable to RSV infection [9]. Further studies are required to determine the relative contributions of these potential mechanisms. Concerning OA-specific $\mathrm{IgG}_{1}$ production, it is well established that some cytokines can regulate the expression of $\mathrm{Ig}$ isotypes [29]. Specifically, Th2 cytokines, such as IL-4 and also IL-13, can regulate Ig-class switching to $\mathrm{IgG}_{1}$ in mice, while IFN- $\gamma$ secreted by Th1 cells inhibits this [30]. Species-specific nucleotide sequences for IL-4 and IL-13 are not known for guinea pigs, thereby precluding their measurement in the current study. Nevertheless, the significantly lower titres of serum OA-specific $\mathrm{IgG}_{1}$ antibodies documented in the CPG-ODN + RSV + OA group versus the $\mathrm{RSV}+\mathrm{OA}$-positive controls in experiment 1 is consistent with the less extensive Th2 shift in lung Th1/Th2 balance (with IL-5 serving as a marker) observed in the CpG-ODN-treated animals.
The results of experiment 2 indicate that CpG-ODN immunotherapy does not prevent guinea pigs from becoming allergically sensitised to OA, despite naïve animals showing a significant Th1 shift in lung Th1/Th2 balance from CpGODN immunotherapy. In mouse models, whether CpG-ODN administration alone can protect against allergic sensitisation is a matter of contention [31, 32], and further studies designed to examine alternative strategies, such as conjugation of CpGODN with allergen, may be warranted [31].

In summary, this study examined the effects of cytosine phosphate-guanine-oligodeoxynucleotides immunotherapy on allergic sensitisation to ovalbumin, with and without concomitant respiratory syncytial virus infection. The results indicate that the pre-treatment of guinea pigs with cytosine phosphate-guanine-oligodeoxynucleotides immunotherapy confers protection against the viral contribution of respiratory syncytial virus-enhanced allergic sensitisation to ovalbumin, and cytosine phosphate-guanine-oligodeoxynucleotides immunotherapy may provide a promising intervention strategy for the subgroup of children whose sequelae of respiratory syncytial virus bronchiolitis are associated with virusenhanced allergic sensitisation.

\section{ACKNOWLEDGEMENTS}

The authors would like to thank S. Greene and D. English for their photographic assistance, and D. Minshall and L. Carter for their assistance in the care of the experimental animals.

\section{REFERENCES}

1 Hall CB. Respiratory syncytial virus and parainfluenza virus. N Engl J Med 2001; 344: 1917-1928.

2 Sigurs N, Bjarnason R, Sigurbergson F, Kjellman B. Respiratory syncytial virus bronchiolitis in infancy is an important risk factor for asthma and allergy at age 7. Am J Respir Crit Care Med 2000; 161: 1501-1507.

3 Schauer U, Hoffjan S, Bittscheidt J, et al. RSV bronchiolitis and risk of wheeze and allergic sensitisation in the first year of life. Eur Respir J 2002; 20: 1277-1283.

4 Schwarze J, Hamelmann E, Bradley KL, Takeda K, Gelfand EW. Respiratory syncytial virus infection results in airway hyperresponsiveness and enhanced airway sensitization to allergen. J Clin Invest 1997; 100: 226-233. 
5 Hegele RG, Robinson PJ, Gonzalez S, Hogg JC. Production of acute bronchiolitis in guinea-pigs by human respiratory syncytial virus. Eur Respir J 1993; 6: 1324-1331.

6 Ishida K, Kelly LJ, Thomson RJ, Beattie LL, Schellenberg RR. Repeated antigen challenge induces airway hyperresponsiveness with tissue eosinophilia in guinea pigs. J Appl Physiol 1989; 67: 1133-1139.

7 al-Laith M, Weyer A, Havet N, Dumarey C, Vargaftig BB, Bachelet M. Immunoglobulin-G-dependent stimulation of guinea pig lung mast cells and macrophages. Allergy 1993; 48: 608-614.

8 Dakhama A, Bramley AM, Chan NG, McKay KO, Schellenberg RR, Hegele RG. Effects of respiratory syncytial virus on subsequent allergic sensitization to ovalbumin in guinea-pigs. Eur Respir J 1999; 13: 976-982.

9 Bramley AM, Khan MA, Manson HE, Hegele RG. Development of respiratory syncytial "bronchiolitis" in guinea pigs does not reflect an allergic predisposition in the host. Chest 2003; 124: 671-681.

10 Hamid Q, Song Y, Kotsimbos TC, et al. Inflammation of small airways in asthma. J Allergy Clin Immunol 1997; 100: 44-51.

11 Tripp RA. The brume surrounding respiratory syncytial virus persistence. Am J Respir Crit Care Med 2004; 169: 778-779.

12 Constant SL, Bottomly K. Induction of Th1 and Th2 CD4+ T-cell responses: the alternative approaches. Annu Rev Immunol 1997; 15: 297-322.

13 Roman M, Calhoun WJ, Hinton KL, et al. Respiratory syncytial virus infection in infants is associated with predominant Th-2-like response. Am J Respir Crit Care Med 1997; 156: 190-195.

14 Kim CK, Kim SW, Park CS, Kim BI, Kang H, Koh YY. Bronchoalveolar lavage cytokine profiles in acute asthma and acute bronchiolitis. J Allergy Clin Immunol 2003; 112: 64-71.

15 Legg JP, Hussain IR, Warner JA, Johnston SL, Warner JO. Type 1 and type 2 cytokine imbalance in acute respiratory syncytial virus bronchiolitis. Am J Respir Crit Care Med 2003; 168: 633-639.

$16 \mathrm{O}^{\prime}$ Garra A, Arai N. The molecular basis of T helper 1 and T helper 2 cell differentiation. Trends Cell Biol 2000; 10: 542-550.

17 Kline JN, Krieg AM. CpG oligodeoxynucleotides. Prog Respir Res 2001; 31: 229-232.

18 Mutwiri G, Pontarollo R, Babiuk S, et al. Biological activity of immunostimulatory CpG DNA motifs in domestic animals. Vet Immunol Immunopathol 2003; 91: 89-103.

19 Horner AA, Raz E. Immunostimulatory sequence oligodeoxynucleotide-based vaccination and immunomodulation: two unique but complementary strategies for the treatment of allergic diseases. J Allergy Clin Immunol 2002; 110: 706-712.

20 Canadian Council on Animal Care. Guide to the care and use of experimental animals. Ottawa, CCAC, 1980.

21 Kaan PM, Hegele RG. Interaction between respiratory syncytial virus and particulate matter in guinea pig alveolar macrophages. Am J Respir Cell Mol Biol 2003; 28: 697-704.

22 Kitagaki K, Businga TR, Kline JN. Differing effects of CpG$\mathrm{A}$ and $\mathrm{CpG}-\mathrm{B}$ on antigen stimulated immune responses. Am J Respir Crit Care Med 2004; 169: A717.

23 Tayyari F, Ashfaq MK, Manson HE, Hegele RH. Comparison of dose and route of administration of $\mathrm{CpG}$ oligonucleotide (CpG-ODN) on pulmonary Th1/Th2 cytokine balance in guinea-pigs. Am J Respir Crit Care Med 2003; 167: A724.

24 Churg A. An inflation procedure for open lung biopsies. Am J Surg Pathol 1983; 7: 69-71.

25 Nolan CR III, Anger MS, Kelleher SP. Eosinophiluria: a new method of detection and definition of the clinical spectrum. N Engl J Med 1986; 315: 1516-1519.

26 Rozen S, Skaletsky HJ. Primer 3 on the WWW for general users and for biologist programmers. In: Krawetz S, Misener S, eds. Bioinformatics methods and protocols: methods in molecular biology. Totowa, Humana Press, 2000; pp. 365-386.

27 Sachs L. Applied statistics: a handbook of techniques. New York, Springler Verlag Publishers, 1982.

28 Rosner B. Hypothesis testing: categorical data. In: Fundamentals of biostatistics. Boston, Duxbury Press, 1982; pp. 171-224.

29 Estes DM, Brown WC. Type 1 and type 2 responses in regulation of Ig isotope expression in cattle. Vet Immunol Immunopathol 2002; 90: 1-10.

30 Lordan JL, Hellewell PG. Cytokines, chemokines, and adhesion proteins. In: Holgate ST, Church MK, Lichtenstein LM, eds. Allergy. 2nd Edn. London, Mosby, 2001; pp. 283-302.

31 Shirota H, Sano K, Kikuchi T, Tamura G, Shirato K. Regulation of T-helper type 2 cell and airway eosinophilia by transmucosal coadministration of antigen and oligodeoxynucleotides containing CpG motifs. Am J Respir Cell Mol Biol 2000; 22: 176-182.

32 Broide D, Schwarze J, Tighe $\mathrm{H}$, et al. Immunostimulatory DNA sequences inhibit IL-5, eosinophilic inflammation, and airway hyperresponsiveness in mice. J Immunol 1998; 161: 7054-7062. 